\title{
Do organic surface films on sea salt aerosols influence atmospheric chemistry? - a model study
}

\author{
L. Smoydzin and R. von Glasow \\ Institute of Environmental Physics, University of Heidelberg, Im Neuenheimer Feld 229, 69120 Heidelberg, Germany \\ now at: School of Environmental Sciences, University of East Anglia, Norwich, UK
}

Received: 21 September 2006 - Published in Atmos. Chem. Phys. Discuss.: 17 October 2006

Revised: 21 March 2007 - Accepted: 24 October 2007 - Published: 6 November 2007

\begin{abstract}
Organic material from the ocean's surface can be incorporated into sea salt aerosol particles often producing a surface film on the aerosol. Such an organic coating can reduce the mass transfer between the gas phase and the aerosol phase influencing sea salt chemistry in the marine atmosphere. To investigate these effects and their importance for the marine boundary layer (MBL) we used the one-dimensional numerical model MISTRA. We considered the uncertainties regarding the magnitude of uptake reduction, the concentrations of organic compounds in sea salt aerosols and the oxidation rate of the organics to analyse the possible influence of organic surfactants on gas and liquid phase chemistry with a special focus on halogen chemistry. By assuming destruction rates for the organic coating based on laboratory measurements we get a rapid destruction of the organic monolayer within the first meters of the MBL. Larger organic initial concentrations lead to a longer lifetime of the coating but lead also to an unrealistically strong decrease of $\mathrm{O}_{3}$ concentrations as the organic film is destroyed by reaction with $\mathrm{O}_{3}$. The lifetime of the film is increased by assuming smaller reactive uptake coefficients for $\mathrm{O}_{3}$ or by assuming that a part of the organic surfactants react with $\mathrm{OH}$. With regard to tropospheric chemistry we found that gas phase concentrations for chlorine and bromine species decreased due to the decreased mass transfer between gas phase and aerosol phase. Aqueous phase chlorine concentrations also decreased but aqueous phase bromine concentrations increased. Differences for gas phase concentrations are in general smaller than for liquid phase concentrations. The effect on gas phase $\mathrm{NO}_{2}$ or $\mathrm{NO}$ is very small (reduction less than 5\%) whereas liquid phase $\mathrm{NO}_{2}$ concentrations increased in some cases by nearly $100 \%$. We list suggestions for further laboratory studies which are needed for improved model studies.
\end{abstract}

Correspondence to: L. Smoydzin

(1.smoydzin@uea.ac.uk)

\section{Introduction}

Aerosol particles are important constituents of the global climate system. With their ability to scatter solar radiation aerosols influence the global energy budget and affect climate directly. Furthermore, they serve as cloud condensation nuclei $(\mathrm{CCN})$ and influence cloud properties like the number distributions and size of droplets. As the scattering of solar radiation depends on these quantities, aerosols also have an indirect effect on the global energy budget.

In the marine boundary layer sulfate and sea salt aerosols which originate from bubble bursting at the ocean surface are the most important particles which can act as CCN.

Apart from their role in cloud processes, aerosol particles are important for atmospheric chemistry as they can take up gas phase species, recycle them and release them back into the gas phase. Furthermore sea salt aerosol particles can be the source for gas phase constituents like halogen species.

More than 20 yeas ago Gill et al. (1983) brought up the idea that organic surfactants which can be present on sea salt aerosols might be of potential importance as they might affect processes like droplet activation and droplet growth.

Both dissolved organic matter and decomposition products from algae accumulate in the surface microlayer. The thickness of this layer depends on the biological activity. Organic matter can be directly incorporated in marine particles when gas bubbles burst at the surface. Furthermore, rising gas bubbles scavenge organic material in the water column when they rise towards the surface. A third way for inclusion of organic matter into sea salt aerosol particles is uptake from the gas phase into airborne particles.

Although it is known that these processes take place it is still a challenge to determine the contribution from the oceanic surface microlayer to the initial chemical composition of sea salt particles which is important for understanding the complete reaction cycles taking place in the atmosphere. Ellison et al. (1999) have developed an inverted

Published by Copernicus Publications on behalf of the European Geosciences Union. 
micelle model to describe atmospheric processing of organic surface films of biological origin on sea borne aerosol particles.

Recent measurements have shown that the organic mass fraction in marine particles can be up to $60 \%$ especially in regions with high biological activity (O'Dowd et al., 2004). Even in areas where only small amounts of microorganisms are present in sea water like the Carribean (Novakov et al., 1997; Russell et al., 2002) and Cape Grim (Middlebrook et al., 1998) non-negligible organic mass fractions were detected. Organic concentrations in marine particle samples vary up to a few orders of magnitude since the biological activity varies and since the organic mass fraction is much larger in the smallest particle modes than in larger modes (O'Dowd et al., 2004). Cavalli et al. (2004) report concentrations of water insoluble organic compounds of $0.66 \mu \mathrm{gm}^{-3}$ in the submicron and $0.26 \mu \mathrm{gm}^{-3}$ in the supermicron mode whereas Sempere and Kawamura (2003) report dicarboxylic acid concentrations of only a few ngm $^{-3}$.

As organic compounds are large in number and complexity most chemical analyses of sea salt aerosols can only give information about functional groups being present in the samples. The measurements from Mace Head have further shown that about $60 \%$ of the total organic mass fraction is water insoluble. The functional groups detected are mainly carbonyl compounds and carboxylic acids (Cavalli et al., 2004; Russell et al., 2002; Sempere and Kawamura, 2003; Mochida et al., 2002) which might be decomposition products of longer chain fatty acids. These compounds are known to be surface active meaning that they are able to form a film on the aerosol which can decrease the mass transfer between the gas phase and the liquid phase as discussed by Gill et al. (1983). However, laboratory measurements show different results regarding the degree of uptake reduction. While $\mathrm{N}_{2} \mathrm{O}_{5}$ uptake on sea salt aerosols covered by an organic coating seems to be decreased by a factor of 3-4 up to a factor of 42 (Thornton and Abbatt, 2005; Badger et al., 2006; Neill et al., 2006) there are measurements which show that uptake of water vapour on particles with a palmitic acid coating is not affected significantly (Garland et al., 2005). Brown et al. (2006) have collected aerosol particles over the American continent and could show that the uptake coefficient for $\mathrm{N}_{2} \mathrm{O}_{5}$ on these particles varies with ambient conditions including the organic mass fraction in the aerosol.

It was assumed that soluble organic compounds being present in sea salt aerosols might have a great influence on droplet activation and droplet growth. Ervens et al. (2005) presented a model study where they could show that the impact of organic aerosol constituents on the microphysical properties of the aerosol might have been overestimated as the effects caused by an alteration of the aerosol's solubility, molecular weight and surface tension counteract one another and lead to only small changes compared with cases where these effects are ignored.

As mentioned above little is known about the chemical composition of the organic mass fraction so that it is very difficult to assess the chemical reactions that take place on the organic aerosol surface and within the aerosol. What has been shown in many studies, however, is that the surfactant coating undergoes chemical reaction with atmospheric oxidants like $\mathrm{O}_{3}$ or $\mathrm{OH}$ which leads to the destruction of the organic coating on the aerosol. Most of the published laboratory studies dealing with the reactive uptake of $\mathrm{O}_{3}$ on coated particles use oleic acid as a proxy for surface active compounds like fatty acids (Moise and Rudich, 2002; Smith et al., 2002; Katrib et al., 2004; Hearn and Smith, 2004; Thornberry and Abbatt, 2004; Knopf et al., 2005; Hung et al., 2005; Hearn et al., 2005; Ziemann, 2005; Zahardis et al., 2005; Katrib et al., 2005; Zahardis et al., 2006). Although the measurements agree quite well in the value for the reactive uptake coefficient it is questionable and has been pointed out in several of these studies if these numbers can be applied under atmospheric conditions where an organic film would consist of a large number of different surfactants. One reason why we maybe should handle these data with care are the large discrepancies in oleic acid lifetimes in the laboratory where the molecules only survive a few seconds opposed to the lifetimes in the atmosphere which seem to be a few days. Robinson et al. (2006) calculated the oxidation lifetime of condensed phase organic aerosol constituents as a function of particle size and compared the results to the age of an aerosol particle in air masses which are affected by regional transport. They suggest that a reactive uptake coefficient for $\mathrm{O}_{3}$ on organic aerosols nearly two orders of magnitude lower than reported from laboratory measurements would be more realistic.

Further measurements deal with the oxidation of organic monolayers by $\mathrm{NO}_{3}$ and $\mathrm{OH}$ which seem to happen on similar time scales (Knopf et al., 2006; Bertram et al., 2001) and with the uptake of $\mathrm{Cl}$ and $\mathrm{Br}$ by organic surfaces (Moise and Rudich, 2001). In addition to the already mentioned processes at the gas phase-surfactant interface the surfactants might also be attacked at the surfactant-aqueous phase interface. However, we were not able to find information about this. Apart from the uncertainties regarding the destruction rate of the film even less is known about reaction products that are formed by the reaction between the organic film with gas phase oxidants and further reaction pathways.

In this paper we investigate the influence of a decreased mass transfer between the gas phase and the liquid phase on atmospheric chemistry which we assume to be the dominant effect of a surfactant coating on sea salt aerosols for chemistry.

Based on model calculations we provide estimates about the lifetime of organic coatings in the atmosphere and up to which altitudes coated sea salt particles can be transported. The influence of the coating on gas phase and liquid phase chemistry is analysed with a focus on halogen chemistry which is strongly influenced by gas and aerosol phase interactions and heterogeneous reactions. 
In Sect. 2 of this paper a model description and the setup for the model runs is presented. In Sect. 3 the influence of a reduced mass transfer due to the organic coating on atmospheric gas and liquid phase chemistry is discussed.

\section{Model description}

For studying the effect of organic surfactants on atmospheric chemistry we use the one-dimensional numerical model MISTRA (von Glasow et al., 2002; von Glasow and Crutzen, 2004) which is a model of the marine boundary layer (MBL). It contains a microphysics scheme and calculates chemistry in the gas phase, in aerosol particles and in cloud droplets. The chemical mechanism contains the most important reactions of $\mathrm{O}, \mathrm{H}, \mathrm{C}, \mathrm{N}, \mathrm{S}, \mathrm{Cl}$, and $\mathrm{Br}$ both in the gas and particulate phase and has been updated according to the IUPAC recommendation (04-2004, see http: //www.iupac-kinetic.ch.cam.ac.uk).

In the model are distinguished sulfate and sea salt aerosol particles which differ by their size $(0.005-0.5 \mu \mathrm{m}$ for sulfate, $0.5-15 \mu \mathrm{m}$ for sea salt) and initial chemical composition. The parameterisation of Monahan et al. (1986) for the emission of sea salt particles by bubble bursting is used.

\subsection{Surface reaction}

In the model the prognostic equation for the concentration of a gas phase chemical species $c_{g}$ (in $\mathrm{mol} / \mathrm{m}_{\text {air }}^{3}$ ) including turbulent exchange, deposition on the ocean surface $(D)$, chemical production $(P)$ and destruction $(L)$, emission $(E)$ and exchange with the aqueous phase is:

$$
\begin{aligned}
\frac{\partial c_{g}}{\partial t}= & \frac{\partial}{\partial z}\left(K_{h} \rho \frac{\partial c_{g} / \rho}{\partial z}\right)-D+P-L c_{g} \\
& +E-\sum_{i=1}^{n_{k c}} \overline{k_{t, i}}\left(L W C_{l, i} c_{g}-\frac{c_{a, i}}{k_{H}^{c c}}\right)
\end{aligned}
$$

where $k_{H}^{c c}$ is the dimensionless Henry constant obtained by $k_{H}^{c c}=k_{H} R T\left(k_{H}\right.$ is in $\left.\mathrm{mol} / \mathrm{m}^{3} \mathrm{~Pa}\right), L W C_{l, i}$ and $c_{a, i}$ are the dimensionless liquid water content and aqueous phase concentration of the aerosol size class $i$ and $n_{k c}$ are the number of aqueous classes. As mentioned above, we focus on limitations of mass transfer from gas to liquid and liquid to gas phase which is described by the sum term of Eq. (1). The rate coefficients for heterogeneous reactions and phase transfer reactions depend on the mass transfer coefficient $k_{t}$ for non-reactive uptake of gas molecules to the surface of particles (Schwartz, 1986) which is given by:

$k_{t}=\left(\frac{r^{2}}{3 D_{g}}+\frac{4 r}{3 \bar{v} \alpha}\right)^{-1}$

with the particle radius $\mathrm{r}$, the mean molecular speed $\bar{v}=\sqrt{8 R T /(M \pi)}$ ( $\mathrm{M}$ is the molar mass), the accommodation coefficient $\alpha$ and the gas phase diffusion coefficient $D_{g}$ which can be approximated by $D_{g}=\lambda \bar{v} / 3$ using the mean free path $\lambda$.

In our setup the parameter influenced by the organic coating is the accommodation coefficient which describes the probability that a gas phase molecule impinging on the particle is taken up.

In contrast to a Langmuir-Hinshelwood uptake description (Kwamena et al., 2006; Poschl et al., 2005) we use an approach where the rate coefficients for the transfer reactions are determined by multiplying $\mathrm{k}_{t}$ with the $L W C$ for the forward reaction $\left(k_{f}\right)$ describing uptake of gaseous species and with the dimensionless Henry coefficient $k_{H}^{c c}$ for the backward reaction $\left(k_{b}\right)$ describing release of liquid phase species (Sander, 1999).

$$
\begin{aligned}
k_{f} & =k_{t} \cdot L W C \cdot c_{g} \\
k_{b} & =k_{t} \cdot \frac{c_{a}}{k_{H}^{c c}}
\end{aligned}
$$

To simulate organic surface films every sea salt particle which is emitted from the ocean is assumed to contain organic compounds. We assumed that one molecule of an organic compound covers $20 \times 10^{-20} \mathrm{~m}^{2}$ of the sea salt aerosol surface. For a particle radius of $3 \mu \mathrm{m}$ an organic concentration of about $0.5 \mathrm{nmol} / 1$ is needed to form a complete monolayer on one particle. In the following, surfactant concentrations refer to the total sea salt particle spectrum so that the required oleic acid concentration to cover all sea salt particles would be about $0.07 \mathrm{~mol} / \mathrm{l}$ for a typical particle spectrum with an average radius of $3 \mu \mathrm{m}$.

As soon as the organic concentration is large enough to form a monolayer on the aerosol the accommodation coefficients $(\alpha)$ for gas phase species are decreased in the model. A reduction of $\alpha$ by one order of magnitude would lead to a decrease in the transfer coefficient $\left(k_{t}\right)$ of about $50 \%$ for a particle with a radius of $0.8 \mu \mathrm{m}$. Figure 1 shows the effect for various reduction factors as a function of particle radius. For the uptake of gaseous species with large transfer coefficients close to the diffusion limit for large particles (as sea salt particles) a reduction of the accommodation coefficient leads to nearly no differences in the transfer coefficient (Fig. 1, $r=10^{-5} \mathrm{~m}$ ).

To describe the heterogeneous reaction between gas phase oxidants and the organic surfactants we calculate a reactive uptake rate with Eq. (2) by replacing the accommodation coefficient $\alpha$ with the reactive uptake coefficient $\gamma$. That means that we use a reactive uptake coefficient instead of an unreactive uptake coefficient. Replacing $\alpha$ by $\gamma$ is strictly only valid if the diffusion corrections for the measured reactive uptake coefficients were low. However, regarding the range of reported reactive uptake coefficients and regarding the uncertainties related to these values one can replace alpha by gamma without causing a large error. By using this approach to calculate a first order reaction rate of the gas phase oxidants with the surfactant, we can calculate both the loss of the oxidant and the chemical destruction of the surfactant. 


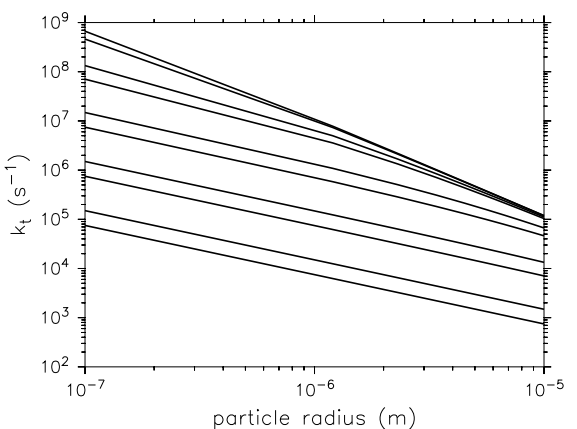

Fig. 1. Transfer coefficient $k_{t}$ as a function of particle radius and accommodation coefficient $\alpha$ calculated after Eq. (2). The largest value chosen for $\alpha$ was 1 (resulting in the largest values for $k_{t}$; $k_{t}=7 \times 10^{8}$ for $r=10^{-7}$ ) and the lowest value was $\alpha=5 \times 10^{-5}$ (resulting in the lowest value for $k_{t} ; k_{t}=7 \cdot 10^{4}$ for $r=10^{-7}$ ). $\alpha$ was decreased stepwise by a factor of 0.5 from 1 to $5 \times 10^{-5}$. The different lines refer to the transfer coefficient calculated with different accommodation coefficients. Note the logarithmic scaling of the axes.

Therefore we explicitly calculate the chemical lifetime of the surfactant. We do not use time-dependant reactive uptake coefficients as the surface film in our model gets completely destroyed by reaction and so the factors that lead to the determination of time-dependant uptake/reaction rates in a laboratory experiment do not account for our model approach.

All model runs were performed for summer time (solar declination $20^{\circ}$ ) under clean marine conditions characterised by relatively low $\mathrm{NO}_{\mathrm{x}}$ and $\mathrm{O}_{3}$ mixing ratios (initial mixing ratios are: $20 \mathrm{nmol} / \mathrm{mol} \mathrm{O}_{3}, 9 \mathrm{pmol} / \mathrm{mol} \mathrm{NO}_{2}, 1.6 \mathrm{pmol} / \mathrm{mol}$ NO). A typical marine background aerosol size distribution (Hoppel and Frick, 1990) with an initial surface area of $70 \mu \mathrm{m}^{2} / \mathrm{cm}^{3}$ is used. We chose the initial and boundary conditions such that no clouds form during the simulation time and the boundary layer height is kept constant at about $700 \mathrm{~m}$. The temperature in the lowest model levels is about $15^{\circ} \mathrm{C}$ and relative humidity increases from $65 \%$ near the ocean surface to $85 \%$ at the top of the boundary layer.

All model runs are initialised with the same fields for chemistry and meteorology which are taken from a two day model run without organic emissions in order to have a spin up for the model. The simulation time for all runs is three days and each run starts at midnight. For all cases except the base case sea salt particles contain organic compounds when they are emitted from the ocean. This setup can be understood as follows: The model column moves over the clean ocean and after two days it crosses for three days an area with high biological activity where organic material gets incorporated into sea salt aerosols.

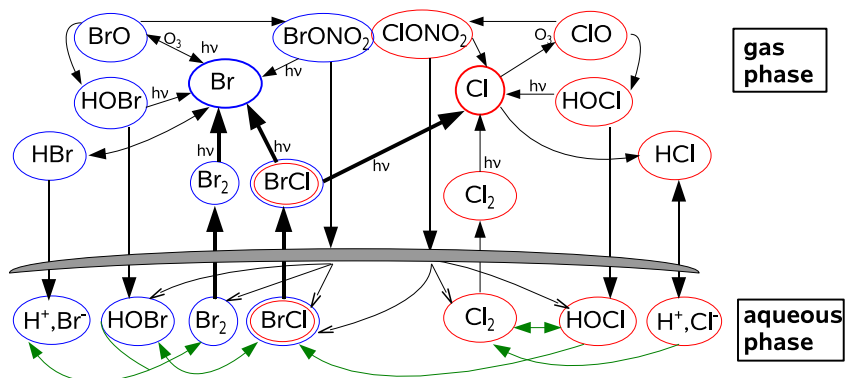

Fig. 2. Bromine and Chlorine cycling between aerosol phase and gas phase.

\subsection{Halogen chemistry}

The most important source for gas phase halogen species in the marine troposphere are sea salt aerosols. As soon as $\mathrm{H}^{+}$ concentrations in the aerosol are large enough $\mathrm{BrCl}$ and $\mathrm{Br}_{2}$ are formed in the aerosol and degas into the gas phase starting a halogen cycling between the aerosol phase and the gas phase (Fig. 2) (Vogt et al., 1996; von Glasow and Crutzen, 2003). Gas phase $\mathrm{BrCl}$ and $\mathrm{Br}_{2}$ are rapidly photolysed during day and form $\mathrm{Br}$ and $\mathrm{Cl}$. Both species can react with $\mathrm{O}_{3}$ and produce the halogen oxides $\mathrm{BrO}$ and $\mathrm{ClO}$ which further react leading to the production of $\mathrm{HOBr}$ and $\mathrm{HOCl}$. The hypohalous acids are taken up by the aerosol where they take part in the acid catalysed reactions forming $\mathrm{BrCl}$ or $\mathrm{Br}_{2}$. $\mathrm{BrO}$ and $\mathrm{ClO}$ can further react with $\mathrm{NO}_{2}$ and produce $\mathrm{BrONO}_{2}$ and $\mathrm{ClONO}_{2}$ which take part in heterogeneous reactions.

\subsection{Setup of model runs}

To quantify the uncertainties regarding the concentrations of organic compounds being present in sea salt aerosols, the magnitude of uptake reduction, the oxidation rate of the organics and the organic fractions being oxidised by reaction with ozone or $\mathrm{OH}$ four different scenarios were considered. In the following we refer to the different scenarios with Roman numbers I-IV and to the different cases with Arabic numbers $1-6$.

\section{Scenario I:}

The model runs for scenario I were performed to investigate the potential influence of different organic concentrations in sea salt aerosols. As mentioned above organic concentrations might vary by more than three orders of magnitude as they are strongly depending on ambient conditions.

For all cases of this scenario it is assumed that the surface film only comprises of oleic acid, which we use as a proxy for long chain organic surfactants and that the film is destroyed by reaction between oleic acid and $\mathrm{O}_{3}$ using literature values for the reactive uptake coefficient (Knopf et al., 2005). The accommodation coefficients of all species are decreased by a 
Table 1. $\alpha_{\circ}$ : accommodation coefficient, $\alpha$ : decreased accommodation coefficient, $\mathbf{O A}$ : initial concentration of oleic acid (respectively

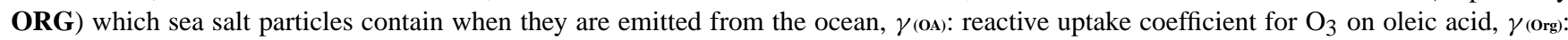
reactive uptake coefficient for $\mathrm{OH}$ on "ORG".

\begin{tabular}{|c|c|c|c|c|c|}
\hline $\begin{array}{l}\text { Scenario I } \\
\alpha=0.1 \cdot \alpha_{\circ} \\
\gamma_{(\mathrm{OA})}=7.9 \cdot 10^{-4}\end{array}$ & $\begin{array}{l}\text { case 1: } \\
\text { case 2: } \\
\text { case 3: }\end{array}$ & $\begin{array}{l}\mathrm{OA}=0.08 \mathrm{~mol} / \mathrm{l} \\
\mathrm{OA}=0.4 \mathrm{~mol} / \mathrm{l} \\
\mathrm{OA}=0.8 \mathrm{~mol} / \mathrm{l}\end{array}$ & $\begin{array}{l}\text { Scenario II } \\
\mathrm{OA}=0.08 \mathrm{~mol} / 1 \\
\alpha=0.1 \cdot \alpha_{\circ}\end{array}$ & $\begin{array}{l}\text { case 1: } \\
\text { case 2: } \\
\text { case 3: }\end{array}$ & $\begin{array}{l}\gamma_{(\mathrm{OA})}=7.9 \cdot 10^{-4} \\
\gamma_{(\mathrm{OA})}=1 \cdot 10^{-5} \\
\gamma_{(\mathrm{OA})}=1 \cdot 10^{-6}\end{array}$ \\
\hline$\gamma_{(\mathrm{Org})}=0.1$ & $\begin{array}{l}\text { case 4: } \\
\text { case 5: } \\
\text { case 6: }\end{array}$ & $\begin{array}{ll}\text { Org }=0.08 \mathrm{~mol} / \mathrm{l} \\
\mathrm{Org}=0.4 \mathrm{~mol} / \mathrm{l} \\
\text { Org=0.8 } \mathrm{mol} / \mathrm{l}\end{array}$ & & & \\
\hline $\begin{array}{l}\text { Scenario II } \\
\alpha=0.1 \cdot \alpha_{\circ} \\
\gamma_{(\mathrm{OA})}=7.9 \cdot 10^{-4} \\
\gamma_{(\mathrm{Org})}=0.1\end{array}$ & $\begin{array}{l}\text { case 1: } \\
\text { case 2: } \\
\text { case 3: }\end{array}$ & $\begin{array}{l}\mathrm{OA}=0.39 \mathrm{~mol} / \mathrm{l} \\
\mathrm{Org}=0.39 \mathrm{~mol} / 1 \\
\mathrm{OA}=0.07 \mathrm{~mol} / \mathrm{l} \\
\mathrm{Org}=0.078 \mathrm{~mol} / \mathrm{l} \\
\mathrm{OA}=0.047 \mathrm{~mol} / \mathrm{l} \\
\mathrm{Org}=0.062 \mathrm{~mol} / \mathrm{l}\end{array}$ & $\begin{array}{l}\text { Scenario IV } \\
\mathrm{OA}=0.4 \mathrm{~mol} / 1 \\
\gamma_{(\mathrm{OA})}=7.9 \cdot 10^{-4}\end{array}$ & $\begin{array}{l}\text { case 1: } \\
\text { case 2: } \\
\text { case 3: }\end{array}$ & $\begin{array}{l}\alpha=0.25 \cdot \alpha_{\circ} \\
\alpha=0.1 \cdot \alpha_{\circ} \\
\alpha=0.025 \cdot \alpha_{\circ}\end{array}$ \\
\hline$\gamma_{(\mathrm{OA})}=1 \cdot 10^{-5}$ & $\begin{array}{l}\text { case 4: } \\
\text { case 5: } \\
\text { case 6: }\end{array}$ & $\begin{array}{l}\mathrm{OA}=0.039 \mathrm{~mol} / \mathrm{l} \\
\mathrm{Org}=0.055 \mathrm{~mol} / \mathrm{l} \\
\mathrm{OA}=0.039 \mathrm{~mol} / \mathrm{l} \\
\mathrm{Org}=0.047 \mathrm{~mol} / \mathrm{l} \\
\mathrm{OA}=0.039 \mathrm{~mol} / \mathrm{l} \\
\mathrm{Org}=0.039 \mathrm{~mol} / \mathrm{l}\end{array}$ & $\begin{array}{l}\mathrm{OA}=0.07 \mathrm{~mol} / 1 \\
\text { Org }=0.078 \mathrm{~mol} / 1 \\
\gamma_{(\mathrm{Org})}=0.1\end{array}$ & $\begin{array}{l}\text { case 4: } \\
\text { case 5: } \\
\text { case 6: }\end{array}$ & $\begin{array}{l}\alpha=0.25 \cdot \alpha_{\circ} \\
\alpha=0.1 \cdot \alpha_{\circ} \\
\alpha=0.025 \cdot \alpha_{\circ}\end{array}$ \\
\hline
\end{tabular}

factor of 10 if an organic coating is present. The initial oleic acid concentrations are varied (case 1-3).

\section{Scenario II:}

The reactive uptake coefficients which we used for the heterogeneous reactions between the organic film compounds and gas phase radicals were all determined under laboratory conditions using single compound organic particles or particles covered by a single-compound-film. However, even a surface film consisting of only two different compounds changes the reactivity of the film (Katrib et al., 2005). In reality a surface film consists of a large number of different organic compounds. A mixed film might alter the chemical properties of a coated aerosol significantly in contrast to the laboratory studies. Therefore we performed model runs with different reactive uptake coefficients for $\mathrm{O}_{3}$ on oleic acid. For this scenario the initial organic concentration was kept constant for all cases and all accommodation coefficients were reduced in the same way as in scenario I.

\section{Scenario III:}

The uncertainty regarding the real composition of an organic film leads to the question how many surface molecules are really oxidised by reaction with $\mathrm{O}_{3}$ and how many molecules react with other oxidants like $\mathrm{OH}$. In scenario III the film consists of different mass fractions of oleic acid (which reacts with $\mathrm{O}_{3}$ ) and "ORG" which is an unspecified organic compound which we assume to react with $\mathrm{OH}$. The reactive uptake coefficient for this reaction is taken from Bertram et al. (2001). Again the accommodation coefficients are reduced by one order of magnitude if an organic film is present. Initial concentrations of both of the organic species were varied indicating that a film has different $[\mathrm{ORG}] /[$ oleic acid] ratios.

\section{Scenario IV:}

Finally we studied the sensitivity of atmospheric gas and aerosol phase chemistry to different magnitudes of uptake reduction. In cases 1-3 of scenario IV the organic surface film consists again only of oleic acid which reacts with $\mathrm{O}_{3}$. The initial oleic acid concentration was the same for all three cases (same setup as case I.2). In cases 4-6 the film consists of oleic acid and ORG (same setup as case III.2). The magnitude of the decrease of the accommodation coefficients was varied. 


\section{Results}

\subsection{Lifetime of the organic film}

Organic surface films on sea salt particles can only have an effect on atmospheric chemistry if they have a lifetime long enough so that they can be transported to higher levels of the MBL.

\section{Scenario I:}

For case 1 of scenario I (blue dash-dotted line, Fig. 3Ia, Ib, Ic) it was assumed that the initial oleic acid concentration for freshly emitted sea salt aerosols is large enough to form exactly one monolayer on the aerosol. The plots Ia, IIa and IIIa of Fig. 3 show the maximum altitude where particles with a complete monolayer can be found. As can be seen in Fig. 3 (Ia), for case I.1 the organic coating is already destroyed within the lowest $30 \mathrm{~m}$ of the boundary layer because the reaction with $\mathrm{O}_{3}$ is very fast. For case I.2 (green dotted line, Fig. 3 Ia,Ib,Ic) and case I.3 (red dashed line, Fig. 3Ia, Ib, Ic) higher initial organic concentrations were assumed. As a consequence, coated particles can be found at higher atmospheric levels during the whole simulation time $(90 \mathrm{~m}$ for case I.2, $140 \mathrm{~m}$ (day)-200 m (night) for case I.3). The differences for case I. 3 between day and night can be explained with the diurnal variation of the turbulence structure in the MBL. Turbulent transport is stronger during night than during day as the air cools down stronger at night than the ocean surface thus inducing thermal turbulence. That explains why coated particles can reach higher levels during night than during day when the sea salt source and the only sink reaction for organic surfactants stay unchanged.

However, the assumptions which were made in scenario I cannot be used for further investigations because after three days of model run we see a dramatic decrease in $\mathrm{O}_{3}$ concentrations by $30 \%$ for case I. 3 compared to the base run without an organic coating (Fig. 3Ic). For case I.1 and case I.2 where oleic acid concentrations are lower the differences are smaller. This effect is caused by the new sink reaction for $\mathrm{O}_{3}$ with oleic acid. With a reactive uptake coefficient of $\gamma=7.9 \times 10^{-4}$, the $\mathrm{O}_{3}$ destruction rate by the heterogeneous reaction with oleic acid is $0.008 \mathrm{pmol} / \mathrm{mol} \mathrm{s}$ which results in the difference of $3.75 \mathrm{nmol} / \mathrm{mol}$ (for case I.3) after three days simulation time. Such a strong $\mathrm{O}_{3}$ loss is not realistic.

\section{Scenario II:}

Therefore, in scenario II the reactive uptake coefficients for $\mathrm{O}_{3}$ on oleic acid are decreased. For case II.3 (red dashed line Fig. 3 IIa, b) the same initial oleic acid concentration as in case II. $1(0.08 \mathrm{~mol} / \mathrm{l}$, green dotted line Fig. $3 \mathrm{IIa}, \mathrm{b})$ is sufficiently large for the presence of coated particles at $500 \mathrm{~m}$ altitude during the whole simulation time, without an unrealistically strong $\mathrm{O}_{3}$ destruction. By changing the reactivity of the film by about one order of magnitude (case II.2, blue dash-dotted line, Fig. 3, IIa) coated particles can be found up to about $100 \mathrm{~m}$.

\section{Scenario III:}

The lifetime of the film can also be increased when we assume that only a small fraction of the organic constituents react with $\mathrm{O}_{3}$ and the largest fraction reacts with $\mathrm{OH}$. For such a scenario an initial concentration of $0.062 \mathrm{~mol} / \mathrm{l}$ for "ORG" and an oleic acid concentration of about $0.047 \mathrm{~mol} / \mathrm{l}$ is sufficient to transport coated particles into upper levels of the boundary layer (case III.3, light blue line, Fig. 3IIIa). However, in case III. 3 coated particles reach altitudes larger than $200 \mathrm{~m}$ only during day and the first hours of the nights. As explained above turbulent transport in the MBL is stronger during night than during day. For case I.3 for which we have chosen the largest initial concentrations for the organics this leads to a larger maximum altitude where coated particles can be found during night ( $200 \mathrm{~m}$, see Fig. 3Ia). For all cases of scenario III (and also cases II.2, II.3) it leads to the opposite effect because stronger turbulent transport also leads to a larger relative humidity during night in the upper levels of the MBL so that aerosol growth is facilitated leading to larger aerosol particles. That means that at altitudes of $200 \mathrm{~m}$ to $700 \mathrm{~m}$ the organic concentration which is needed to form a complete monolayer is slightly larger during night than during day. The concentration differences between cases III.1 (red dash-dotted line, Fig. 3IIIa, b, c), III.2 (green dotted line, Fig. 3IIIa, b, c), III.3 (light blue line, Fig. 3IIIa, b, c) and III.4 (black line, Fig. 3IIIa, b, c) at these altitudes are very small but sufficiently large to find coated particles at $500 \mathrm{~m}$ altitude also during night in case III.1 and III.2 but not in case III.3. and III.4.

In case III.5 (blue dashed line, Fig. 3IIIa, b, c) and case III.6 (purple line, Fig. 3IIIa, b, c) where oleic acid and "ORG" concentrations were low but the reactivity of the film was decreased, coated particles can reach at least an altitude of about $100 \mathrm{~m}$ to $300 \mathrm{~m}$.

Even though the reactive uptake coefficient for $\mathrm{OH}$ on organic aerosols is much larger than for $\mathrm{O}_{3}$ on oleic acid the reaction rate for the reaction $\mathrm{OH}+\mathrm{ORG}$ is not as fast as for $\mathrm{O}_{3}+$ oleic acid. $\mathrm{OH}$ is a very short lived radical with concentrations that are several orders of magnitude lower than for $\mathrm{O}_{3}$ and with gas phase sink reactions up to three orders of magnitude faster than the heterogeneous reaction with the organic film. In contrast to this the reaction with the surfactants becomes one of the fastest $\mathrm{O}_{3}$ sink reactions leading to its strong destruction as discussed above. This explains the slow destruction of the organic film if it predominantly reacts with $\mathrm{OH}$. For scenario III the lifetime of the film is further increased because $\mathrm{OH}$ is not present during night and no other sink reaction for the organic surfactants ("ORG") are taken into account. 
Ia)

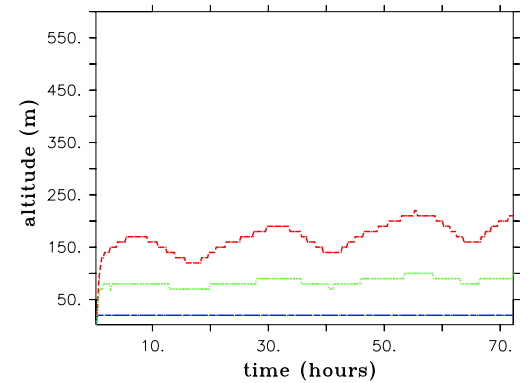

IIa)

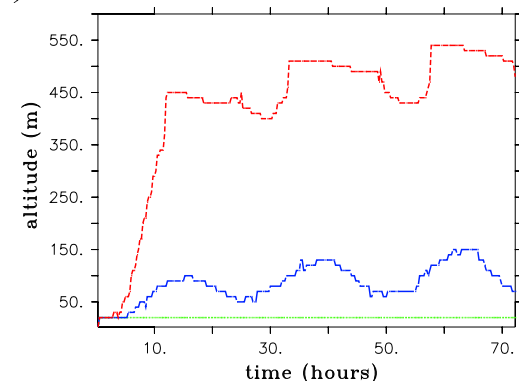

IIIa)

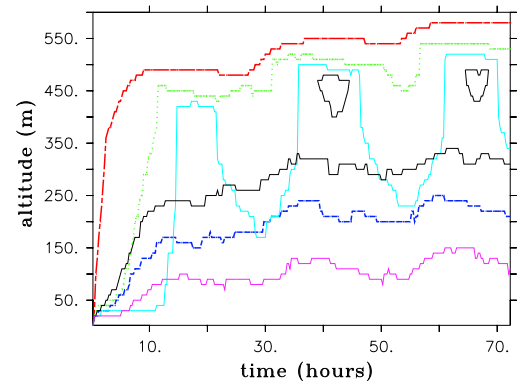

Ib)

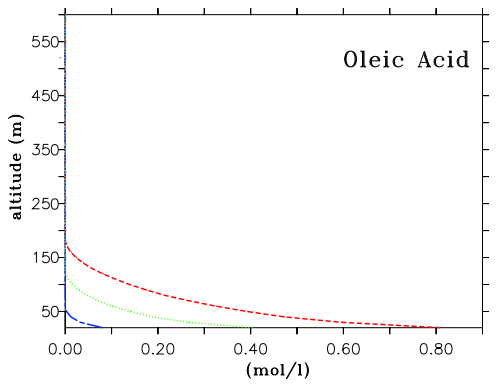

IIb)

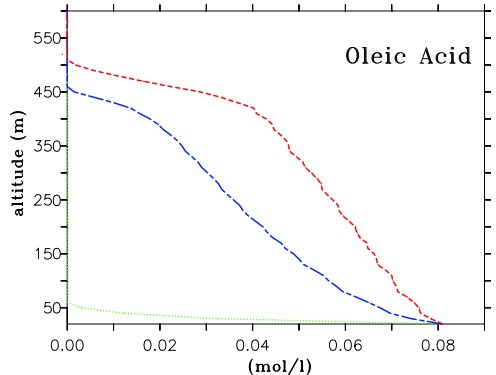

IIIb )

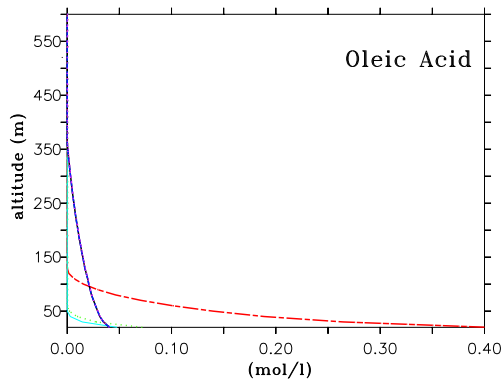

Ic)

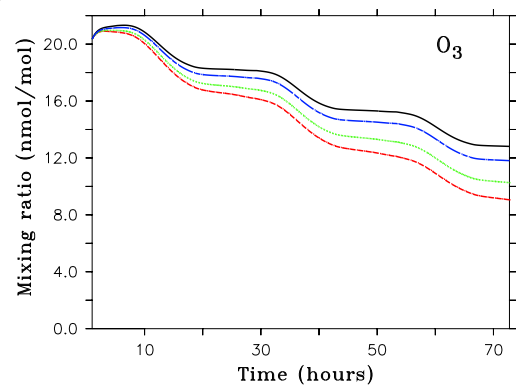

IIIc)

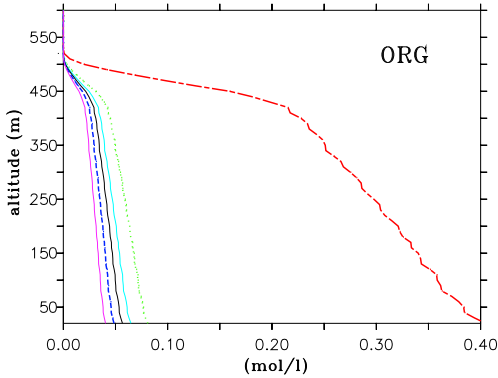

Fig. 3. The colour code for the plots is as follows: Plots for cases of Scenario I (Ia, Ib, Ic): base case (black solid), I.1 (blue dash-dotted), I. 2 (green dotted), I.3 (red dashed), I.4 (black dashed), I.5 (purple dash-dotted), I.6 (light blue dotted). Plots for cases of Scenario II (IIa, IIb): II.1 (green dotted), II.2 (blue dash-dotted), II.3 (red dashed). Plots for cases of Scenario III (IIIa, IIIb, IIIc): III.1 (red dash-dotted), III.2 (green dotted), III.3 (light blue line), III.4 (black line), III.5 (blue dashed), III.6 (purple line).

Figures Ia, IIa, IIIa: Levels below which sea salt aerosols are coated with an organic film. Figures Ib, IIb, IIIb: Vertical profile of oleic acid concentrations at noon, third day of simulation. As for scenario III, case III.4, III.5 and III.6 initial oleic acid concentrations were the same, the lines for these cases are on top of each other (III b). Figure Ic: 3-day time series of gas phase $\mathrm{O}_{3}$ mixing ratios at $50 \mathrm{~m}$ altitude. The time is given in hours since model start. Figure IIIc: Vertical profile of "ORG" concentrations at noon, third day of simulation.

To summarise the results from Sect. 3.1 one can say:

- If $50 \%$ of the organics were to react with $\mathrm{OH}$ and $50 \%$ with $\mathrm{O}_{3}$ and reactive uptake coefficients determined in the laboratory are valid under atmospheric conditions, then the initial concentration of both species have to be larger than $0.04 \mathrm{~mol} / 1$ so that coated particles are present at least in the lowest 50 meters of the MBL or above.

- If more than $50 \%$ of the organics react with $\mathrm{OH}$, an initial ORG concentration of $0.07 \mathrm{~mol} / 1$ and an initial oleic acid concentration of $0.078 \mathrm{~mol} / \mathrm{l}$ is enough to find covered particles even at 400-500 meters altitude (case III.2).

- To survive long enough in the atmosphere to be important, either i) the largest fractions of the organic film have to be compounds that react with $\mathrm{OH}$ (or at least that do not react with $\mathrm{O}_{3}$ ) when assuming that measured reactive uptake coefficients are correct (cases III.2, III.3), or ii) if about $50 \%$ of the organics should react with $\mathrm{O}_{3}$ (cases II.2, III.6) the reaction rates have to be about a factor of five smaller than those derived in the laboratory.

For accurately modelling the effect of a reduced mass transfer due to organic surfactants on sea salt aerosols it is very important to know how long the organic coating is complete and how far coated particles can be transported upward because the longer the lifetime of the film the larger is its possible influence.

However, we could show in this section that a lot of uncertainties exist so that small changes in the initial organic con- 

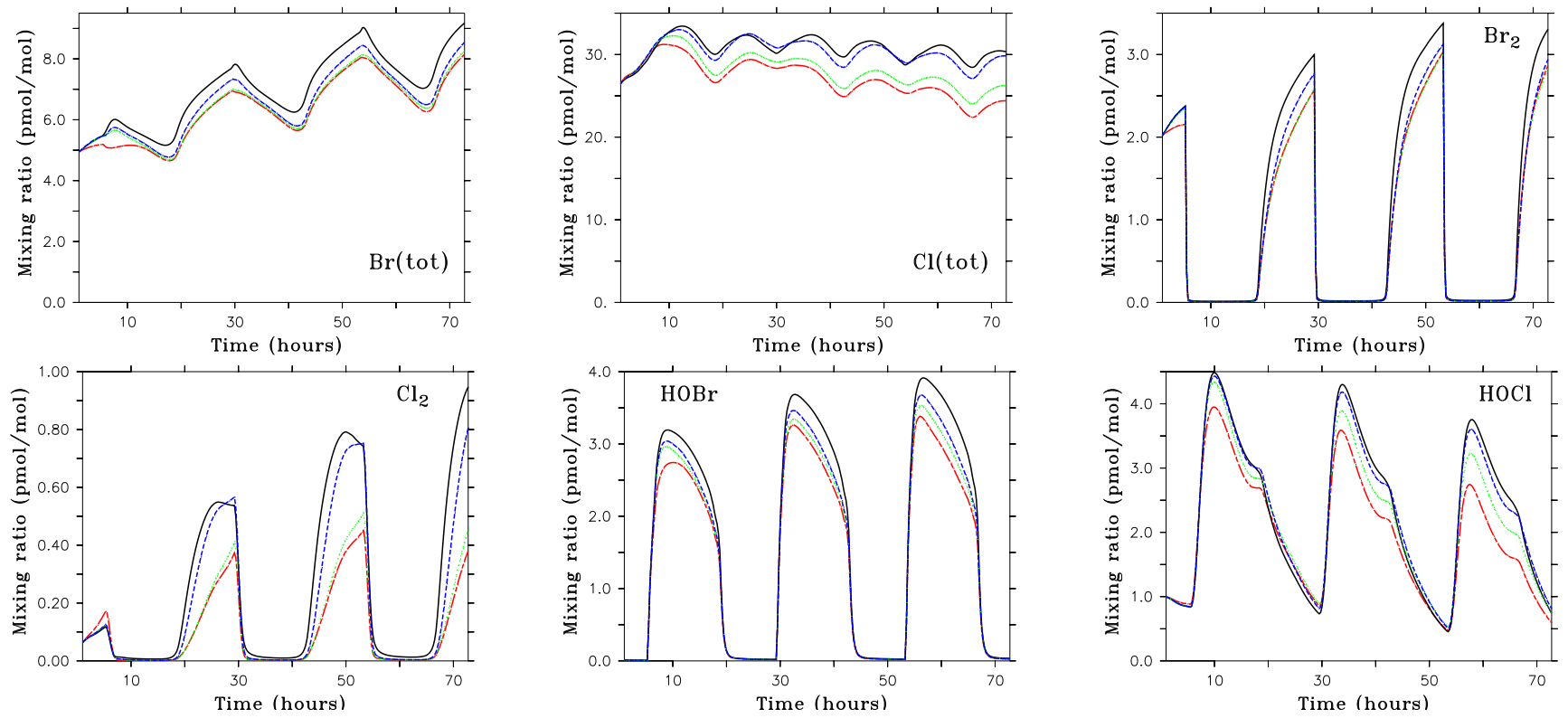

Fig. 4. Scenario III: Time evolution of gas phase mixing rations at $50 \mathrm{~m}$ altitude for three days (midnight day $1-$ midnight day 3 ). The time is given in hours since model start. Case III.1 (red, dash-dotted), case III.2 (green, dotted), case III.5 (blue, dashed), base case (black, solid line). $\mathrm{Br}_{\text {tot }}=\mathrm{HBr}+\mathrm{HOBr}+\mathrm{BrNO}_{2}+\mathrm{BrNO}_{3}+2 \cdot \mathrm{Br}_{2}+\mathrm{BrCl}+\mathrm{Br}+\mathrm{BrO} \mathrm{Cl}_{\text {tot }}=\mathrm{HCl}+\mathrm{HOCl}+\mathrm{ClNO}_{2}+\mathrm{ClNO}_{3}+2 \cdot \mathrm{Cl}_{2}+\mathrm{Cl}+\mathrm{ClO}+\mathrm{OClO}+2 \cdot \mathrm{Cl} \mathrm{O}_{2}+\mathrm{BrCl}$

centrations or the reactive uptake coefficients lead to large differences in the lifetime of the film.

In order to study the effects, we had to make assumptions regarding: (i) The density of organic molecules on the aerosol surface. We made the assumption that one molecule of oleic acid is located directly next to the adjacent molecule but it might be possible that organics do not have to be packed this tightly on the aerosol surface to influence mass exchange between gas and liquid phase. Laboratory measurements show that a monolayer of loosely packed organic compounds can still have an influence on the uptake behaviour (Neill et al., 2006) so that we might overestimate initial surfactant concentrations in our model and the related ozone loss. (ii) The reactive uptake coefficients for gas phase oxidants on organic surfactants. Even though numerous measurements for uptake coefficients exist the published values are not applicable under atmospheric conditions and sensitivity studies were necessary to show the range of resulting different lifetimes dependant on the reactive uptake coefficients. (iii) The composition of the film and decomposition products. As a realistic composition of the film is unknown the surface activity of decomposition products is not known. Every assumption about the reactivity of decomposition products and their ability to be surface active would be speculative so that we did not take into account any further reactions of the initial components of the monolayer. It should be kept in mind that in reality a lot more reactions on the aerosol surface take place that might increase the lifetime of the organic coating but that might increase or decrease the reactivity of the film compared to the laboratory measurements.

\subsection{Effects of reduced mass transfer on chemistry}

The net effect of the decreased mass transfer due to an organic coating on atmospheric chemistry mainly depends on the lifetime of the film. Therefore results from scenario II and III are very similar and only scenario III is discussed in more detail in this section. It can be expected that especially those species are influenced by the decreased mass transfer due to an organic coating that i) directly take part in heterogeneous reactions or uptake processes; or ii) species that take part in acid catalysed reactions.

Sea salt aerosols get rapidly acidified in the atmosphere by uptake of acids like $\mathrm{HNO}_{3}$ or $\mathrm{H}_{2} \mathrm{SO}_{4}$. These processes are slowed down by the organic surface film leading to slightly higher gas phase concentrations and lower aqueous phase concentrations of acids in contrast to the base case. Although the uptake of acids is decreased, the decrease of $\mathrm{H}^{+}$concentrations is relatively small and the aerosol $\mathrm{pH}$ is hardly changed when it is compared with the base case (Fig. 5). Only in the case with highest rates for the surface reaction (case III.1) the pH increases from 5.60 to 5.65 at day three of the simulation. These differences are too small to significantly influence aqueous phase chemistry and acid catalysed aqueous phase reactions.

We focus our discussion on tropospheric halogen chemistry because concentrations of halogen species are strongly controlled by exchange processes between the gas and the aqueous phase as well as by the acidity of the aerosol.

In Fig. 4 the mixing ratios of total gas phase bromine and chlorine species are plotted. For all cases the concentrations 

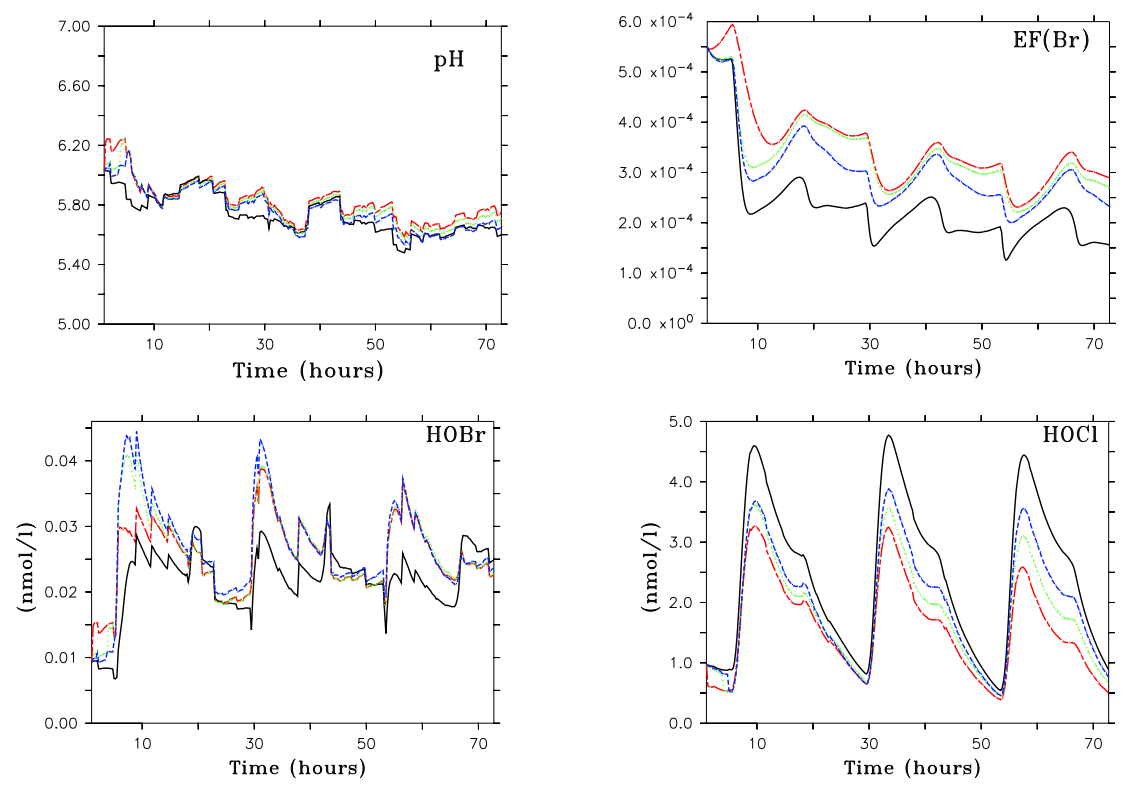

Fig. 5. Scenario III: Time evolution of aqueous phase concentrations at $50 \mathrm{~m}$ altitude for three days (midnight day $1-$ midnight day 3 ). The time is given in hours since model start. Case III.1 (red, dash-dotted), case III.2 (green, dotted), case III.5 (blue, dashed), base case (black, solid line).

are lower than without an organic coating (black line) which has to be attributed to the decreased mass transfer out of the liquid phase. However, the difference after three days of simulation time is only $9 \%$ for total bromine. For gas phase chlorine concentrations the same effect can be observed but the differences are larger (10\%-20\% for case III.1). This trend can be observed for nearly all species, i.e. $\Delta \mathrm{Cl}$ : $20-30 \%$, $\Delta \mathrm{ClO}: 20-40 \%, \Delta \mathrm{Cl}_{2}: 50-80 \%, \Delta \mathrm{HOCl}: 10-30 \%$ versus $\Delta \mathrm{Br}: 5-15 \%, \Delta \mathrm{BrO}: 15-25 \%, \Delta \mathrm{Br}_{2}: 20-30 \%$ or $\Delta \mathrm{HOBr}$ : $15-20 \%$.

During day, one of the main sources for gas phase $\mathrm{Cl}$ and $\mathrm{Br}$ is the photolysis of $\mathrm{BrCl}$ which degasses out of the aerosol. Due to the organic coating less $\mathrm{BrCl}$ gets into the gas phase leading to a reduced $\mathrm{Cl}$ and $\mathrm{Br}$ production by this reaction pathway (Fig. 2). A second important source for $\mathrm{Br}$ is the photolysis of $\mathrm{Br}_{2}$ which also degasses more slowly out of the aerosol when an organic coating is present. A corresponding source for $\mathrm{Cl}$ is photolysis of $\mathrm{Cl}_{2}$. However, this reaction is about $80 \%$ slower than photolysis of $\mathrm{Br}_{2}$. The lower $\mathrm{Br}$ and $\mathrm{Cl}$ gas phase concentrations lead to lower concentrations of their reaction products like $\mathrm{HOBr}, \mathrm{HBr}, \mathrm{BrONO}_{2}$ and, respectively, $\mathrm{HOCl}, \mathrm{HCl}$ and $\mathrm{ClONO}_{2}$ which are taken up by the aerosol or take part in heterogeneous surface reactions $\left(\mathrm{ClONO}_{2}, \mathrm{BrONO}_{2}\right)$. Uptake and surface reactions are also slowed down so that less bromine and chlorine are transported from the gas phase into the aerosol phase compared to the base case.

In Fig. 5 concentrations of aqueous phase $\mathrm{HOBr}$ and $\mathrm{HOCl}$ are plotted. It can be seen that $\mathrm{HOCl}$ concentrations decreased and $\mathrm{HOBr}$ concentrations increased when an organic coating was present on sea salt aerosols compared to the base case. A very important reaction for starting bromine chemistry in the aqueous phase is the conversion of $\mathrm{Br}^{-}$into $\mathrm{Br}_{2}$ or $\mathrm{BrCl}$ by the following reactions:

$$
\begin{array}{ll}
\mathrm{HOBr}+\mathrm{Br}^{-}+\mathrm{H}^{+} \longleftrightarrow \mathrm{Br}_{2} & (5,-5) \\
\mathrm{HOBr}+\mathrm{Cl}^{-}+\mathrm{H}^{+} \longleftrightarrow \mathrm{BrCl} & (6,-6)
\end{array}
$$

Both reactions are equilibrium reactions which usually produce $\mathrm{Br}_{2}$ and $\mathrm{BrCl}$ in the forward Reactions $(5,6)$. If the organic film is present, $\mathrm{Br}_{2}$ and $\mathrm{BrCl}$ accumulate in the aqueous phase because the transfer into the gas phase is decreased. As a consequence the reverse Reactions $(-5,-6)$ gain in importance and produce $\mathrm{HOBr}$ and $\mathrm{Br}^{-}$leading to larger $\mathrm{HOBr}$ aqueous phase concentrations compared to the base case. Equivalent reactions take place including $\mathrm{HOCl}$ instead of $\mathrm{HOBr}$ and lead to the production of $\mathrm{Cl}_{2}$ and $\mathrm{BrCl}$ without considering the effect of the organic coating.

$$
\begin{aligned}
& \mathrm{HOCl}+\mathrm{Cl}^{-}+\mathrm{H}^{+} \longleftrightarrow \mathrm{Cl}_{2} \\
& \mathrm{HOCl}+\mathrm{Br}^{-}+\mathrm{H}^{+} \longrightarrow \mathrm{BrCl}
\end{aligned}
$$

However, these reactions are slower and the reverse reaction of Reaction (8) is negligible. As a result with an organic coating more $\mathrm{HOCl}$ is consumed because of larger $\mathrm{Br}^{-}$concentrations but less $\mathrm{Cl}_{2}$ is produced because $\mathrm{Cl}^{-}$concentrations are hardly affected by the coating.

The shifting of the equilibria due to the decreased mass transfer between gas phase and liquid phase explains the increased concentrations of aqueous phase bromine species. For aqueous phase chlorine this shift does not take place 
which explains the decreased concentrations in comparison with the base case. Figure 5 also shows the bromine enrichment factor which is defined as follows:

$$
E F(\mathrm{Br})=\frac{\left(\frac{\left[\mathrm{Br}^{-}\right]}{\left[\mathrm{Na}^{+}\right]}\right)_{\text {particle }}}{\left(\frac{\left[\mathrm{Br}^{-}\right]}{\left[\mathrm{Na}^{+}\right]}\right)_{\text {seawater }}}
$$

The $\mathrm{Br}$ enrichment factor is about $30-40 \%$ higher for case III.1 compared to the base run. This case shows the largest differences because the lifetime of the organic coating is longer than in other cases and sea salt aerosols which contain a surfactant monolayer reach larger altitudes than in the other simulated cases. Bromine species like $\mathrm{HOBr}$, $\mathrm{BrCl}, \mathrm{HBr}$ show differences in the range of $30 \%$ compared to the base case (in contrast to about $20 \%$ in the gas phase). $\mathrm{HOCl}$ aqueous phase concentrations decrease by about 40 $50 \%$. Aqueous phase chemistry seems to be affected more by organic coatings than gas phase chemistry.

As less aqueous phase chlorine is present in model runs with a surfactant coating even less chlorine can degas in comparison to bromine and in comparison with the base case. This explains why gas phase chlorine concentrations decrease much stronger than bromine concentrations. When less gas phase chlorine is produced, smaller amounts can also be taken up by the aerosol so that the effect intensifies itself.

Apart from halogen chemistry other species are also affected by the decreased mass transfer due to the organic film. For the aqueous phase higher concentrations for $\mathrm{NO}_{2}$ $\left(\Delta \mathrm{NO}_{2}: 100 \%\right), \mathrm{NO}_{2}^{-}, \mathrm{HONO}$ and $\mathrm{NO}_{3}$ can be observed as the concentrations of theses species depend on uptake processes. However, the absolute concentrations of all those species are very low so that the relatively small deviation from the base case does not influence any other processes.

For the gas phase nearly no difference in $\mathrm{NO}, \mathrm{NO}_{2}$ or $\mathrm{N}_{2} \mathrm{O}_{5}$ concentrations are found. However, all model runs were performed under clean marine conditions with very low $\mathrm{NO}_{\mathrm{x}}$ mixing ratios.

\subsection{Impact of magnitude of uptake decrease}

In all scenarios discussed above it was assumed that if sea salt aerosols are completely covered with an organic monolayer the accommodation coefficient is reduced by one order of magnitude. Literature values for the strength of uptake reduction vary from a factor of 3-4 (Thornton and Abbatt, 2005) to a factor of 42 (Badger et al., 2006). To quantify how chemistry responds to different uptake behaviour onto sea salt aerosols we performed sensitivity studies where the accommodation coefficients for gas phase species were reduced by various orders of magnitude (Table 1, scenario IV). For cases IV.1-IV.3 the initial organic concentrations were relatively small so that the maximum altitude where particles with a complete monolayer can be found is $90 \mathrm{~m}$ (similar setup than for case I.2, Fig. 3, Ia, green line). For cases IV.4 IV.6 the same initial conditions were chosen as for case III.2 so that coated particles can be found at $400 \mathrm{~m}$ altitude during the whole simulation time (Fig. 3, IIIa, green dotted).

In Fig. 6 time series of total gas phase chlorine and total gas phase bromine concentrations at $50 \mathrm{~m}$ altitude are plotted for scenario IV. Apparently gas phase chemistry is not very sensitive to the magnitude of uptake reduction for cases IV.1IV.3 (Fig. 6a-d). A decrease of the accommodation coefficient by a factor of 4 (case IV.1) leads to $4 \%$ smaller concentrations for total $\mathrm{Br}$ and about $6 \%$ smaller concentrations for total $\mathrm{Cl}$ compared to the base case. Surprisingly, the concentrations hardly decrease any further $(6 \%$ for $\mathrm{Br}$ and $\mathrm{Cl})$ in case IV. 3 where uptake was decreased by about two orders of magnitude. Similar effects can be observed for nearly all gas phase species. As a decrease of the accommodation coefficient by two orders of magnitude leads to a decrease of the mass transfer coefficient by about one order of magnitude only (Fig. 1) the differences in reaction velocities for the cases of scenario IV are less than one order of magnitude.

Larger differences between the three cases can be observed for the liquid phase like it can be expected from the results from scenario III. The $\mathrm{Br}$ enrichment factor is increased by $10-30 \%$ for case IV.1, 20-40\% for case IV.2 and 40-90\% for case IV. 3 compared to the base case. The differences increase with simulation time indicating that the enrichment of $\mathrm{Br}$ in the aerosol due to the organic coating gets stronger the longer the monolayer is present.

Sea salt $\mathrm{pH}$ does not increase significantly for cases IV.1 and IV.2 but it increases from about 5.6 (base case, day 3) to about 6.4 for case IV.3. In comparison with the results from scenario III a long-lived organic coating with a relatively low uptake reduction (scenario III) has more influence on atmospheric chemistry than a short-lived organic monolayer with a relatively large uptake reduction (scenario IV, case 1-3).

For cases IV.4-IV.6 where the lifetime of the organic coating is long, chemistry is much more sensitive to the magnitude of uptake reduction as can be seen in Fig. 6e and $\mathrm{f}$. When the destruction of the organic coating is slow and the accommodation coefficient is reduced by about two orders of magnitude total bromine concentrations decrease by about $20 \%$ and the enrichment factor increases even by about $100 \%$.

\section{Conclusions}

We investigated the influence of a reduced mass transfer between gas phase and aerosol phase caused by an organic surfactant coating on tropospheric chemistry with a special focus on halogen species. Our simulations show that gas phase bromine and chlorine concentrations decrease in the presence of an organic monolayer on sea salt aerosols. Chlorine gas phase chemistry is affected stronger than bromine chemistry. The effect of a reduced mass transfer on aqueous phase chemistry is stronger than on gas phase chemistry leading 
a)

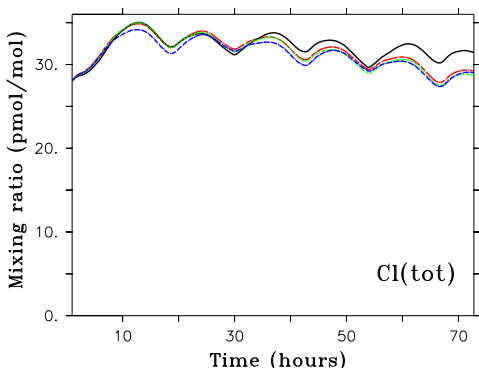

c)

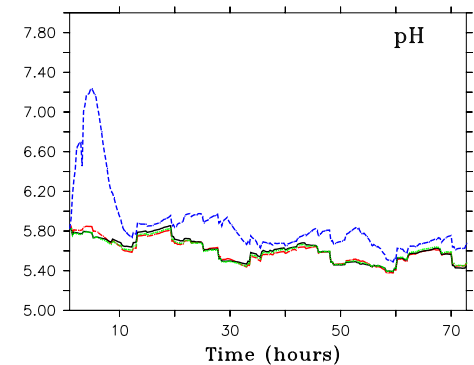

b)

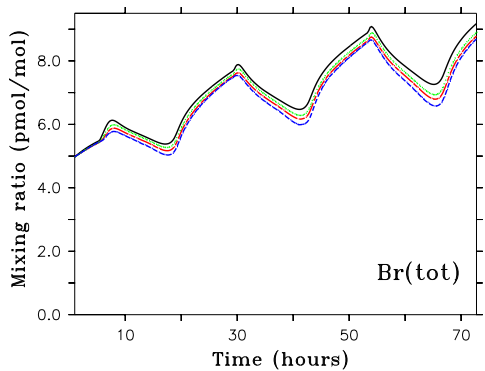

d)

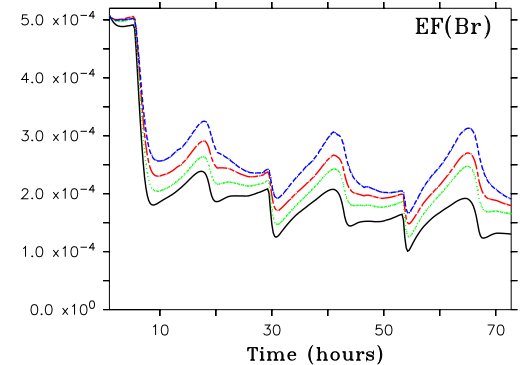

e)

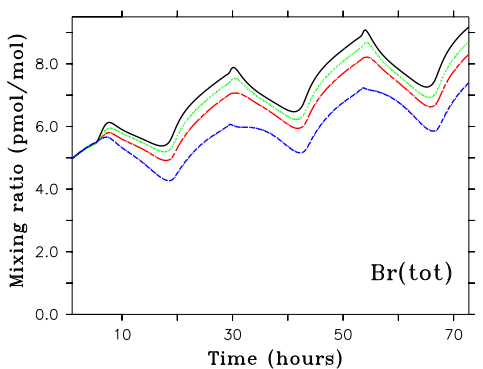

f)

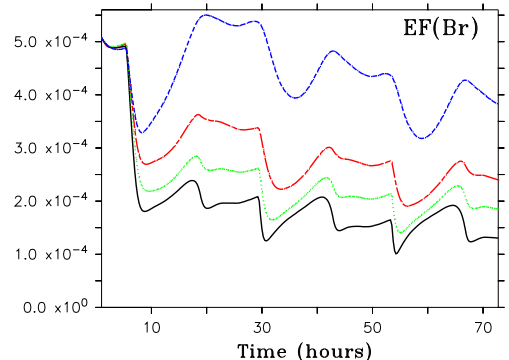

Fig. 6. Scenario IV: Upper row: Mixing ratios of total gas phase bromine and chlorine. Lower row: Bromine enrichment factor and $\mathrm{pH}$. All plots show time series at $70 \mathrm{~m}$ altitude for three days (midnight day 1 - midnight day 3 ).

Plots (a-d) refer to cases IV.1-IV.3. The colour code is as follows: case IV.1 (green, dotted), case IV.2 (red, dash-dotted), case IV.3 (blue, dashed), base case (black,solid line). Plots (e), (f) refer to cases IV.4-IV.6. The colour code is as follows: case IV.4 (green, dotted), case IV.5 (red, dash-dotted), case IV.6 (blue, dashed), base case (black,solid line).

to an increase in bromine concentrations and a decrease in chlorine concentration.

Even though the presence of a coating reduces the uptake of acids, the $\mathrm{pH}$ of the sea salt aerosol is not influenced until we decrease uptake by nearly two orders of magnitude.

We have shown that under conditions where the lifetime of the organic coating is long enough so that coated particles can be found in upper levels of the boundary layer during the whole simulation time tropospheric chemistry might be affected by the decreased mass transfer due to the organic coating. However, very small changes in the model setup lead to large differences in the behaviour of the surfactants pointing out the existing uncertainties.

Assuming that the majority of organic surfactants react with ozone and using the reactive uptake coefficient reported from laboratory studies we get a dramatic decrease in ozone concentrations after three days of simulation time. This effect let us to assume that either a multicomponent coating alters uptake behaviour in such a way that reactive uptake coefficients from laboratory studies cannot be applied under atmospheric conditions or only a very small fraction of the organic surfactants react with $\mathrm{O}_{3}$ and the largest fraction reacts with $\mathrm{OH}$ or $\mathrm{NO}_{3}$.

It is very difficult to draw a clear conclusion from our model runs regarding the effect of an organic surface film on atmospheric chemistry due to the large range of uncertainties concerning the data from laboratory and due to the numerous assumptions we had to make in our model setup. For future model studies we need more and detailed information regarding the following points:

- More detailed data from laboratory measurements are needed that give information how strongly the exchange between gas phase and aerosol phase is really affected by an organic coating. We need to know the magnitude of uptake reduction for various chemical species. It can be supposed that the influence of the organic coating varies depending on each species which is taken up by the aerosol.

- Can we assume that the release of aqueous phase species out of the aerosol is affected in the same way as the uptake of gas phase species into the aerosol?

- How tightly has the organic coating to be packed to influence mass exchange? Again, we need this information related to the uptake behaviour of various chemical species. The density of the organic coating determines the organic concentrations required to influence mass transfer and it determines indirectly the loss rate for gas phase oxidants which react with the surfactants.

- We need more measurements giving us data about organic surfactants which are found in the marine boundary layer and their concentrations.

- It is important to understand the process of surfactants forming films on aerosol particles and the process of destruction of this film by using oleic acid as a proxy for 
surfactants. However, in order to assess the importance for tropospheric chemistry we need a more realistic description of the composition of an organic surface film and its destruction rate.

- We could show that the effect of a reduced mass transfer strongly depends on the lifetime of a surface film in the atmosphere and the lifetime mainly depends on its chemical destruction. Reactive uptake coefficients for a variety of species are required as well as information in which way a mixed surface film alters its properties.

- Knowledge about the breakdown products of surfactants and their properties is required for a more in depth assessment of the problem. Current laboratory studies give information about secondary chemistry of the oleic acid-ozone system only. Even for this system the available information is not detailed enough. That makes the inclusion of these processes in atmospheric chemistry models difficult.

Acknowledgements. This project was funded by the Deutsche Forschungsgemeinschaft DFG (Emmy Noether Junior Research Group MarHal GL 353/1-2). We thank the anonymous referees that helped to improve the manuscript.

Edited by: Y. Balkanski

\section{References}

Badger, C. L., Griffiths, P. T., George, I., Abbatt, J. P. D., and Cox, R. A.: Reactive Uptake of $\left(\mathrm{N}_{2} \mathrm{O}_{5}\right)$ by Aerosol Particles Containing Mixtures of Humic Acid and Ammonium Sulfate, J. Phys. Chem. A, 110(21), 6986-6994, 2006.

Bertram, A. K., Ivanov, A. V., Hunter, M., Molina, L. T., and Molina, M. J.: The Reaction Probability of $\mathrm{OH}$ on Organic Surfaces of Tropospheric Interest, J. Phys. Chem. A, 105, 94159421, 2001.

Brown, S. S., Ryerson, T. B., Wollny, A. G., Brock, C. A., Peltier, R., Sullivan, A. P., Weber, R. J., Dube, W. P., Trainer, M., Meanher, J. F., Fehsenfeld, F. C., and Ravishankara, A. R.: Variability in Nocturnal Nitrogen Oxide Processing and Its Role in Regional Air Quality, Science, 311, 69-70, 2006.

Cavalli, F., Facchini, M. C., Decesari, S., Mircea, M., Emblico, L., Fuzzi, S., Ceburnis, D., Yoon, Y. J., O’Dowd, C. D., Putaud, J.-P., and Dell'Acqua, A.: Advances in characterization of size-resolved organic matter in marine aerosol over the North Atlantic, J. Geophys. Res., 109, D24215, doi:10.1029/2004JD005137, 2004.

Ellison, G. B., Tuck, A. F., and Vaida, V.: Atmospheric processing of organic aerosol, J. Geophys. Res., 104, 11 633-11 641, 1999.

Ervens, B., Feingold, G., and Kreidenweis, S. M.: Influence of water-soluble organic carbon on cloud drop number concentration, J. Geophys. Res., 110, D18211, doi:10.1029/2004JD005634, 2005.

Garland, R. M., Wise, M. E., Beaver, M. R., DeWitt, H. L., Aiken, A. C., Jimenez, J. L., and Tolbert, M. A.: Impact of palmitic acid coating on the water uptake and loss of ammonium sulfate particles, Atmos. Chem. Phys., 5, 1951-1961, 2005, http://www.atmos-chem-phys.net/5/1951/2005/.

Gill, P. S., Graedel, T. E., and Weschler, C. J.: Organic films on atmospheric aerosol particles, fog droplets, cloud droplets, raindrops, and snowflakes, Rev. Geoph. Space Ph., 21, 903-920, 1983.

Hearn, J. D. and Smith, G. D.: Kinetics and Product Studies for Ozonolysis Reactions of Organic Particles using Aerosol CMIS, J. Phys. Chem., 108, 10 019-10 029, 2004.

Hearn, J. D., Lovett, A. J., and Smith, G. D.: Ozonolysis of oleic acid particles: evidence for a surface reaction and secondary reactions involving Crigee intermediates, Phys. Chem. Chem. Phys., 7, 501-511, 2005.

Hoppel, W. A. and Frick, G. M.: Submicron aerosol size distributions measured over the tropical and south Pacific, Atmos. Environ., 24A, 645-659, 1990.

Hung, H.-M., Katrib, Y., and Martin, S. T.: Products and mechanisms of the Reaction of Oleic Acid with Ozone and Nitrate Radical, J. Phys. Chem., 109, 4517-4530, 2005.

Katrib, Y., Martin, S. T., Hung, H.-M., Rudich, Y., Zhang, H., Slowik, J. G., Dividovits, P., Jayne, J. T., and Worsnop, D. R.: Products and Mechanisms of Ozone Reactions with Oleic Acid for Aerosol particles Having Core-Shell Morphologies, J. Phys. Chem., 108, 6686-6695, 2004.

Katrib, Y., Biskos, G., Buseck, P. R., Davidovits, P., Jayne, J. T., Mochida, M., Wise, M. E., Worsnop, D. R., and Martin, S. T.: Ozonolysis of Mixed Oleic-Acid/Stearic-Acid Particles: Reaction Kinetics and Chemical Morphology, J. Phys. Chem., 109, 10910-10919, 2005.

Knopf, D. A., Anthony, L. M., and Bertram, A. K.: Reactive Uptake of $\mathrm{O}_{3}$ by Multicomponent and Multiphase Mixtures Containing Oleic Acid, J. Phys. Chem., 109, 5579-5589, 2005.

Knopf, D. A., Mark, J., Gross, S., and Bertram, A.: Does atmospheric processing of saturated hydrocarbon surfaces by $\mathrm{NO}_{3}$ lead to volatilization, Geophys. Res. Lett., 33, L17816, doi:10.1029/2006GL026884, 2006.

Kwamena, N.-O. A., Earp, M. E., Young, C. J., and Abbatt, J. P. D.: Kinetic and Product Yield Study of the Heterogeneous Gas-Surface Reaction of Anthracene and Ozone, J. Phys. Chem. A, 110, 3638-3646, 2006.

Middlebrook, A. M., Murphy, D. M., and Thomson, D. S.: Observations of organic material in individual marine particles at Cape Grim during the First Aerosol Characterization Experiment (ACE 1), J. Geophys. Res., 103, 16 475-16483, 1998.

Mochida, M., Kitamori, Y., Kawamura, K., Nojiri, Y., and Suzuki, K.: Fatty acids in the marine atmosphere: Factors governing their concentrations and evaluation of organic films on sea-salt particles, J. Geophys. Res., 107, 4325, doi:10.1029/2001JD001278, 2002.

Moise, T. and Rudich, Y.: Uptake of $\mathrm{Cl}$ and $\mathrm{Br}$ by organic surfaces - a perspective on organic aerosols processing by tropospheric oxidants, Geophys. Res. Lett., 28, 4083-4086, 2001.

Moise, T. and Rudich, Y.: Reactive Uptake of Ozone by AerosolAssociated Unsaturated Fatty Acids: Kinetics, Mechanism, and Products, J. Phys. Chem. A, 106, 6469-6476, 2002.

Monahan, E. C., Spiel, D. E., and Davidson, K. L.: A model of marine aerosol generation via whitecaps and wave disruption, in: Oceanic Whitecaps, edited by: Monahan, E. C. and Niocaill, G. M., 167-174, D. Reidel, Norwell, Mass, 1986. 
Neill, V. M., Patterson, J., Wolfe, M., and Thornton, J. A.: The effect of varying levels of surfactant on the reactive uptake of $\left(\mathrm{N}_{2} \mathrm{O}_{5}\right)$ to aqueous aerosol, Atmos. Chem. Phys., 6, 1635-1644, 2006, http://www.atmos-chem-phys.net/6/1635/2006/.

Novakov, T., Corrigan, C., Penner, J., Chuang, C., Rosario, O., and Bracero, O. M.: Organic aerosols in the Caribbean trade winds: A natural source?, J. Geophys. Res., 20, 21 307-21 313, 1997.

O’Dowd, C. D., Facchini, M. C., Cavalli, F., Ceburnis, D., Mircea, M., Descari, S., Fuzzi, S., Yoon, Y. J., and Rutaud, J.-P.: Biogenically driven organic contribution to marine aerosol, Nature, 431, 676-677, 2004.

Poschl, U., Rudich, Y., and Amman, M.: Kinetic model framework for aerosol and cloud surface chemistry and gas-particle interactions: Part 1 - general equations, parameters, and terminology, Atmos. Chem. Phys. Discuss., 5, 2111-2191, 2005, http://www.atmos-chem-phys-discuss.net/5/2111/2005/.

Robinson, A. L., Donahue, N. M., and Rogge, W. F.: Photochemical oxidation and changes in molecular composition of organic aerosol in the regional context, J. Geophys. Res., 111, D03302, doi:10.1029/2005JD006265, 2006.

Russell, L. M., Maria, S. F., and Myneni, S. C. B.: Mapping organic coatings on atmospheric particles, Geophys. Res. Lett., 29(16), doi:10.1029/2002GL014874, 2002.

Sander, R.: Modeling Atmospheric Chemistry: Interactions between Gas-Phase Species and Liquid Cloud/Aerosol Particles, Surv. Geophys., 20, 1-31, 1999.

Schwartz, S. E.: Mass-Transport Considerations Pertinent to Aqueous Phase Reactions of Gases in Liquid-Water Clouds, in Chemistry of Multiphase Atmospheric Systems, edited by: Jaeschke, W., 415-471, NATO ASI Series, Vol. G6, 1986.

Sempere, R. and Kawamura, K.: Trans-hemispheric contribution of C2-C10 alpha omega-dicarboxylic acids and related polar compounds to water-soluble organic carbon in the western Pacific aerosols in relation to photochemical oxidation reactions, Global Biogeochem. Cycles, 17, 1069, doi:10.1029/2002GB001980, 2003.

Smith, G. D., Ephraim Woods, I., DeForest, C. L., Baer, T., and Miller, R. E.: Reactive Uptake of Ozone by Oleic Acid Aerosol Particles: Application of Single-Particle Mass Spectrometry by Heterogeneous Reaction Kinetics, J. Phys. Chem., 106, 80858095, 2002.
Thornberry, T. and Abbatt, J.: Heterogeneous reaction of ozone with liquid unsaturated fatty acids: Detailed kinetics and gasphase product studies, Phys. Chem. Chem. Phys., 6, 84-93, 2004.

Thornton, J. A. and Abbatt, J. P. D.: $\left(\mathrm{N}_{2} \mathrm{O}_{5}\right)$ Reaction on Submicron Sea Salt Aerosol: Kinetics, Products, and the Effect of Surface Active Organics, J. Phys. Chem., 109, 10 004-10 012, 2005.

Vogt, R., Crutzen, P. J., and Sander, R.: A mechanism for halogen release from sea-salt aerosol in the remote marine boundary layer, Nature, 383, 327-330, 1996.

von Glasow, R. and Crutzen, P. J.: Tropospheric halogen chemistry, in: The Atmosphere (ed. R. F. Keeling), Vol. 4 Treatise on Geochemistry, edited by: Holland, H. D. and Turekian, K. K., 21-64, Elsevier-Pergamon, Oxford, 2003.

von Glasow, R. and Crutzen, P. J.: Model study of multiphase DMS oxidation with a focus on halogens, Atmos. Chem. Phys., 4, 589608, 2004,

http://www.atmos-chem-phys.net/4/589/2004/.

von Glasow, R., Sander, R., Bott, A., and Crutzen, P. J.: Modeling halogen chemistry in the marine boundary layer 1 . Cloud-free MBL, J. Geophys. Res., 107, 4341, doi:10.1029/2001JD000942, 2002.

Zahardis, J., LaFranchi, B. W., and Petrucci, G. A.: Photoelectron resonance capture ionization-aerosol mass spectrometry of the ozonolysis products of oleic acid particles: Direct measure of higher molecular weight oxygenates, J. Geophys. Res., 110, D08307, doi:10.1029/2004JD005336, 2005.

Zahardis, J., LaFranchi, B. W., and Petrucci, G. A.: Direct observation of polymerization in the oleic acid-ozone heterogeneous reaction system by photoelectron resonance capture ionization aerosol mass spectrometry, Atmos. Environ., 40, 1661-1670, 2006.

Ziemann, P. J.: Aerosol products, mechanisms, and kinetics of heterogeneous reactions of ozone with oleic acid in pure and mixed particles, Faraday Discuss., 130, 1-22, 2005. 